\title{
LA JUSTICIA CONSTITUCIONAL
}

Anibal Quiroga León*

Asŕ, por una parte, al lado del venerable Estado de Derecho liberal e individualista, que ya cumplió su mision histórica, ha surgido el Estado de Derecho democrático y de carácter social [...] Pero este Estado democrático y social de nuestra época. desde otro punto de vista también puede calificarse como "Estado de. Justicia", en la medida en que ha instituido un sistema adecuado para lograr la efectividad de las normas supremas, en las cuales ha consagrado los ideales, tan dificiles y angustiosamente logrados, del nuevo Derecho Contemporáneo.

Héctor Hix-Zamudio

\section{INTRODCCCION}

El presente trabajo es una reformulación de la exposición efectuada en un Seminario (1), cuyo objetivo principal no fue ana-

(*) Profesor Ordinario de Derecho Procesal Civil y Metodología de la Investigación. Juridica y Secretario Académico de la Facultad de Derecho de la PUC del Perú.

(1) Ponencia sustentada en el Seminario Derechos Humanos y el Sistema Juridico realizado en Arequipa, entre el 21 y 24 de abril de 1987, coorganizado por la Secretaría Ejecutiva del Consejo Nacional de Derechos Humanos del Ministerio de Justicia y el Ilustre Colegio de Abogados de Arequipa. 
lizar con gran profundidad y detenimiento lo que es materia del presente desarrollo, ni su auditorium era necesariamente especializado, ni siquiera familiarizado con la materia. Por ello, como primera cuestión, considero importante salvar su contenido --en los términos que se exponen- de un análisis como el que probablemente el tema merecería dada su innegable trascendencia. sino indicar de manera preliminar los grandes aspectos del misno, a guisa de introducción o acicate a la investigación de esta temática dentro de nuestra vida constitucional, sobre todo a partir de la vigencia de la Constitución de 1979 en que se crea el Tribunal de Garantías Constitucionales en el Perú.

También resulta obligatorio señalar, por un sentimiento de elemental equidad, el agradecimiento al Ilustre Colegio de Abogados de Arequipa que nos permitió desarrollar esta materia ante un considerable número de asistentes en un bello local, colmado en gran parte por abogados y estudiantes ávidos del conocimiento del Sistema Jurídico Peruano y su interrelación con los Derechos Humanos.

El concepto de Justicia Constitucional o, como también se le denomina, Jurisdicción Comstitucional (2) surge con el proceso

(2) Sobre la denominación apareceria contradicción y discrepancia. Asi, FIX-ZAMUDIO (Veinticinco años de evolución de la Justicia Constitucional. 1940.1965; Inst. de Investigaciones Jurídicas; UNAM, Méxi* co, 1968) la denomina así permanentemente; en tanto que GARCIA BELAUNDE (Protección Procesal de los Derechos Fundamentales en la Constitución Peruana de 1979; Rev. "DERECHO" No. 35; P.A. de Derecho de la PUC del Perú, Lima, 1981) opta por la de Jurisdicción Constitucional. En el fondo, bien visto, no hay diferencia sustantiva y serán utilizados como equivalentes, aún cuando el segundo aparezca más sugerente. Sin embargo, la denominación de Justicia Constitucio. nal me parece mäs envolvente. Finalmente, no pasa de ser un problema de diferente óptica de partida, entre un procesalista (FIX-ZAMUDIO) y un iusfilósofo (GARCIA BELAUNDE). Ver también el Prólogo de GARCIA BELAUNDE a la obra de BOREA ODRIA, El A mparo y el Habeas Corpus en el Peru de Hov: Biblioteca Peruana de Derecho Constitucional, Lima, 1985; p. 11 ; asi como el ensayo El control jurisdiccio. nal de la Constitucionalidad de las normas juridicas de carácter general de SOUSA CALLE y DANOS ORDOÑES en: La Constitución Peruana de 1979 y sus problemas de aplicación; Ed. Cuzco S.A., Lima, 1987, pp 281 y ss. 
mismo de la constitucionalización del Estado Moderno. Surge cuando el avance del constitucionalismo determina la supremacía de las normas constitucionales por sobre aquella de la legislación ordinaria, cuando para ello se requiere de la defensa -y sus mecanismos- de esa categoría especial de norma positiva determinada en el texto constitucional.

En consecuencia, podemos afirmar que la jurisdicción o Justicia Constitucional surge entre finales del Siglo XVIII y principios del Siglo XIX, luego de la independencia de los Estados Unidos y de la Revolución Francesa, a la par con el especial proceso de constitucionalización que ocurre en Inglaterra a la muerte de CROMWELL en 1658 (3). Como lo apunta el propio SCHMITT (4), en Alemania también se produjo el mismo fenómeno en el Siglo XIX, aunque las luchas constitucionales germánicas no puedan compararse con las grandes revoluciones mundiales que cambiaron la historia del hombre moderno. No obstante, señala, las constituciones de la Monarquía Constitucional alemana no olvidan el problema de la supremacía constitucional como se aprecia de las Constituciones de Baviera de 1818 de Sajonia de 1831 (5).

Por Justicia Constitucional, o Jurisdicción Constitucional, entonces, podemos entender aquel proceso histórico surgido del propio desarrollo constitucional de los Estados Modernos de derecho, que establecieron mecanismos de control, autocontrol y de defensa de la supremacía y vigencia constitucional.

Es FIX-ZAMUDIO (6) quien señala que en un principio los alemanes, precisamente a partir de SCHMITT, fueron quienes utilizaron primero la definición de Defensa de la Constitución (Der llïter der Verfassung), para luego variarlo al de Justicia Constitucional (Verfassungsgerichtsbarkeit) a partir de la Constitución del WEIMAR de 1919. Los franceses utilizaron preferentemente el

(3) SCHMITT, Carl. La Defensa de la Constitución. Ed. Tecnos S.A., Madrid, 1983; pp. 27 y ss. Prólogo de Pedro DE VEG Manuel SANCHEZ SARTO.

(.t) Op. Cit.

(i) Op. Cit.

(6) FIX-ZAMUDIO, Ifenter. ()p. Cit. p. 12. 
concepto de Control de la Constitucionalidad, en tanto que un sector de los juristas italianos se refieren a la giturisdizione constituzio. nale o al proceso constitutizionale; siendo para los angloamericanos la denominación frecuente la de Judicial Review o revisión judicial de la Constitución.

Al igual que FIX-ZAMUDIO (7), hemos elegido el término de Justicia Constitucional para designar este trabajo preliminar, no obstante lo anotado líneas arriba (8), para designar a los instrumentos de garantía de las disposiciones constitucionales, pretendiendo con ello subrayar su carácter preponderantemente axiológico, valorativo, que persiguen los instrumentos que se han establecido para lograr la efectividad y garantía de las normas fundamentales, las constitucionales; ya que dichas normas contienen no sólo las bases de organización y funcionamiento de los organismos de poder, sino también, y de manera muy esencial, los principios valorativos y gnoseológicos supremos conforme a los cuales debe informarse todo el ordenamiento jurídico a que se halla subordinado en función de un determinado texto constitucional (9).

Es desde este punto de vista que la doctrina italiana nos habla tanto de las disposiciones fundamentales de exigencia inmediata, como de las disposiciones valorativas de principio, dentro de las cuales debemos destacar las llamadas normas programáticas (10), que son aquellas en las que el constituyente ha trazado las orientaciones básicas para el desarrollo del orden politico, jurídico, social. económico y nacional. Esta es la misma idea expresada por el tratadista italia no MAURO CAPPELLETTI (11), quien con gran agudeza explicaba: "En la concepción más moderna, la norma constitucional no es otra cosa que un cnsayo. tal vez imposible, y casi ca-

(7) Op. Cit. p. 13

(8) Ver supra Nota 2

(9) QUIROGA LEON, Anıal. La Interpretación Constitucional; en "DE. RECHO" No. 39. Facultad de Derecho de la PUC del Perú; Lima, 1985. pp. 323 y ss.

(10) FIX-ZANIUDIO, Héctor. ()p. Cit.

(11) Lin una de las conferencias sustentadas en los Cursos de Invierno, en ol mes de febrero de 1965, y publicadas posteriormente en el volumen El Control . Iudicial de la Constitucionalidad de las Leyes on el Derecho Comparado; Cit. por FIX-Z AMUDIO, Héctor. Op. Cit. y cita No. 18. 
lificado de 'faistico', pero profundamente humano y digno de ser intentado. de transformar en derecho escrito lo que hasta ahora han sido supremos valores, la pretensión de 'encerrar' $v$ 'definir' en una norma positiva. lo que por su propia naturaleza es inasible e indefinible: lo absoluto".

\section{VATURALEZA}

Ahora ya resulta tradicional entender que los términos de "control" y "defensa" de la Constitución abarcan dos aspectos diversos: el primero que podemos denotar como de protección de la Ley Suprema, que se ocupa del estudio de los instrumentos que desle siempre se han empleado para la conservación del orden fundamenta1, procurando un equilibrio entre los diversos factores de poder que interaccionan entre sí mismos, y que de modo gráfico pueden ser referidos como los "aspectos fisiológicos" del propio orden constitucional (12).

Pero, precisamente al lado de estos medios tradicionales de protección constitucional, han surgido instrumentos procesales que se emplean cuando resultan insuficientes los primeros para evitar el desbordamiento de los órganos de poder, que no obstante los pre-citados mecanismos de contención, terminan superándolos y así, infringiendo disposiciones constitucionales.

A estos instrumentos procesales de garantía constitucional (13), cuyo objeto es precisamente el reintegrar el orden jurídico constitucional violentado, se les puede describir, también gráficamente, como agrupados bajo el concepto de "instrumentos terapéuticos" que tienden a corregir los desórdenes "patológicos" de la Carta Fundamental (14).

(12) Op. Cit. p. 14

(13) Al lado de lo que se ha venido en conocer como el Derecho Constitucional Procesal, se ha generado (debido al estrechamiento entre el Derecho Procesal y el Derecho Constitucional) la disciplina más joven del procesalismo científico: el Derecho Procesal Constitucional. Ver QUIROGA LEON, Anibal. Los Derechos Humanos, el Debido Proceso y las Garantias Constitucionales de la Administración de Justicia; Ed. Cuzco S.A., Lima, 1987, pp. 97 y ss.

(14) FIX-ZaMudio, Héctor. Op. Cit. 
Es a este Derecho Justicial -al decir de la Escuela Alemana de Derecho Procesal propiciada por GOLDSCHMIDT (15)-que está referida la Justicia Constitucional, que resulta así concebida como un conjunto de procedimientos de carácter procesal-constitucional, por medio de los cuales la propia Constitución -al establecer los ámbitos de competencia del ejercicio del poder - encomienda a determinados Organos del Estado, la imposición forzada de los mandamientos jurídicos-axiológicos fundamentales, frente a aquellos otros orga nismos públicos del propio Estado - y también a los particulares - que han desbordado, precisamente, sus limitaciones competenciales, sus atribuciones de poder y los derechos que la Carta Fundamental les exigía cautelar.

\section{CATEGORIAS FUNDAMENTALES}

Como ya señaláramos, en principio y de manera muy genérica, se puede afirmar que la estructura de un sistema de Justicia Constitucional surge con la Constitución de los Estados Unidos de Norte América de 1787, aún cuando es bien cierto que de modo rudimentario y casi impensado. Se podria afirmar que surge sobre esa base y como producto de una necesidad histórica antes que de la idea preconcebida del constituyente de las antiguas Colonias norteamericanas. Este no tuvo una idea muy precisa sobre el alcance de las facultades de Justicia Constitucional que atribuyeron al Organo Judicial ordinario, por lo que fue la propia jurisprudencia judicial de sus tribunales comunes quienes desarrollaron los postulados básicos de la Justicia Constifucional, sobre todo a partir de un sonado caso judicial que ya es historia jurídica en los Estados Unidos: MARBURY vrs. MADISOV resuelto en 1803 por la Suprema Corte de los Estados Unidos bajo la augusta presidencia del Juez John MARSHALL, donde se estableció literalmente (15)

(15) PAREJA PAZ SOLDAN, José. Derecho Constitucional Peruano y la Constitución de 1979; J. Valenzuela. Ed. Lima. 1980; T. II. p. 445 y cit. 3. Ver, además, Bernard SCHWARTZ en Los Diez Mejores Jueces de la Historia Norteamericana; Ed. Civitas S.A., Madrid, 1985; con la traducción de Enrique ALONSO GARCIA, quien en la p. 22, cit. 13, señala: "la citada sentencia es sin lugar a dudas una de las más conocidas en todo el ámbito jurídico mundial, ya que como es sabido, fue la primera que concientemente institucionalizó el "judicial review" o control judicial de la constitucionalidad. (...) Tan sólo conviene recordar dos aspectos: $1^{\circ} \mathrm{El}$ mejor resumen de la polémica norteamerica- 
que: "La Constitución es una ley suprema y soberana. no susceptible de ser modificada por medios ordinarios, o bien está a nivel de las leyes ordinarias y como todas las otras leyes puede ser modificada. Si la primera parte de la alternativa es cierta, una ley contraria a la Constitución no es ley; si la última parte es verdadera, las Constituciones escritas son tentativas absurdas de parte del pueblo para limitar un poder que por su naturaleza misma no puede ser limitado". Concluyendo que el Juez puede decidir sobre los conflictos entre una ley y la Constitución y considerar como nula "una ley de legislatura repugnante a la Constitución" (16).

A partir de allí, sobre la base del Stare Decisis (precedente vinculante $u$ obligatorio) que jalona el sistema jurídico y judicial de los Estados Unidos, Magistrados de la talla de JOSEPH STORY, OLIVER WENDELL HOLMES y otros (17), desarrollaron con mayor amplitud y sistematicidad el sistema del control judicial de la constitucionalidad de las leyes y de los actos, en lo que se ha venido a denominar el Sistema Americano o de la Judicial Review - Revisión Judicial de la Constitucionalidad - (18).

na acerca de si el "judicial review" estaba o no en la mente de los constituyentes está contenido en la introducción de ALAN F. WESTIN a la obra de BEARD, The Supreme Court and the Constitution, ed. por Prentice-Hall, Inc., en 1962; $2^{\circ}$ No son quizás tan conocidos los antecedentes de hecho que motivaron la sentencia. El ex-presidente de los Estados Unidos John Adams habia nombrado para un cargo a Marbury cuando aquél todavía era presidente, pero el Secretario de Estado Madison se negaba a otorgarle la credencial de nombramiento. Marbury pidio al Tribunal Supremo que dictara "Writ of Mandamus" para obligarle a hacerlo. La Judiciary Act de 1789 autorizaba al Tribunal Supremo a dictarlo, pero la Constitución no parecia permitirlo. Marshall en realidad "aprovechó" la ocasión para sentar el principio".

(16) "Marshall transformó al Tribunal (Supremo) en un poder plenamente coordinado, dotado de la autoridad suprema que supone ser el guardión de la Constitución. Al final de la era Marshall pudo TOCQUEVILLE: afirmar que 'el Tribunal Supremo está situado en un lugar más alto que el que ocupa cualquier otro Tribunal conocido (...) La paz, la prosperidad y la existencia misma de la Unión están en las manos de siete jueces federales"'. Op. Cit. p. 26.

(17) Op. Cit. Además, ver Carl BRENT SWISHER, El desarrollo Constitucional de los Estados Unidos, T. I., Bs. As., 1958, pp. 88 y ss. Cit., por FIX-ZAMUDIO, Héctor. Op. Cit, p. 16.

(18) Op. Cit. pp. 17-18. 
El Sistema Americano o de la Judicial Review' -también conocido como el sistema "difuso" del control de la constitucionalidad-, basa su estructura de Justicia Cons.itucional en el propio Poder Judicial u Organo Jurisdiccional. Es decir, bajo este sistema de Justicia Constitucional es el propio Poder Judicial ordinario quien ejerce el control y defensa de la Constitución a nivel nacional.

De acuerdo a los principios que informan este sistema, cualquier juez puede declarar la inconstitucionalidad de una norma positiva, o de un acto de gobierno, con una validez Erga Omnes, esto es, con efectos derogatorios o rescisorios generales. Siguiendo este esquema, el Parlamento o Poder Legislativo sanciona una norma que cobra de inmediato vigencia e imperatividad de acuerdo a su propia naturaleza interna. En principio, suscitada una controversia judicial donde dicho precepto deba ser aplicado o donde el derecho público subjetivo en disputa deba su realidad a la norma en cuestión, el juzgador ordinario encuentra que la misma colisiona con los postulados constitucionales. Como quiera que la Constitución es una norma legal de carácter especial y de suprema jerarquía y rango, pues determina la estructura básica de la Nación, al ingresar en colisión con una norma legal de inferior jerarquía ha de tener mayor imperio que la norma colisionante pues un principio elemental de lógica jurídica nos indica que dos normas contradictorias no pueden ser válidas a un mismo tiempo o en mismo lugar (19), determinando en el caso concreto la desaparición de la norma colisionante por inconstitucionalidad. Y esta desaparición judicialmente determinada es, en realidad, una derogación o rescisión decretada por autoridad judicial mediante mandato contenido en sentencia. A partir de allí nadie, ni ciudadanos ni autoridades, deben obediencia alguna a dicha norma legal ordinaria cuya inconstitucionalidad ha sido puesta al descubierto por el juzgador ordinario.

El Sistema Europeo de Justicia Constitucional -denominado también Control Ad-Hoc de la Constitución o Sistema Concen-

(19) Aun cuando referida al Derecho Procesal, la inferencia es válida en el presente caso para nuestro tema. Ver: Eduardo J. COUTURE, Fundamentos del Derecho Procesal, 2. Ciencia y Técnica del Proceso, 3era. Ed. -Póstuma-, Eds. De Palma; Bs. As., 1985, p. 487. 
trado de Control de la Constitucionalidad-.., tiene su punto de inicio a partir de la notable -y solitaria - obra del jurista vienés HANS KELSEN (20). GARCIA DE ENTERRIA (21) se admira y sostiene que resulta sorprendente que el constitucionalismo europeo quedase totalmente al margen de la formidable contrucción que supuso el sistema de la Judicial Review en el sistema americano, lo que sólo es explicable - señala - a partir de la degradación de la idea constitucional que supuso la prevalencia del "principio monárquico" como fuente formal de la Constitución. La recepción europea del sistema de justicia constitucional no va a tener lugar hasta la primera gran post-guerra de 1919 , por dos vías principales: una primera a partir de la compleja articulación que supuso el Imperio Alemán y la Monarquía Autro-Húngara y que concluye con la Constitución alemana del WEIMAR, creando un Tribunal al que se confiere la facultad de decidir sobre los conflictos entre los poderes constitucionales y, especialmente, entre los distintos entes territoriales propios de una organización federal; en tanto que la segunda, a partir de la segunda gran post-guerra, y que tiene su punto de partida, precisamente en la ya referida obra genial de KELSEN, en el sistema expresado por primera vez en la Constitución austríaca de 1920 perfeccionado con la reforma de 1929 (21).

Antes de que KELSEN divulgara su obra - con sus postulados sobre la Teoria General del Derecho. Teoria Pura del Derecho y el Positivismo Jurídico que nos alcanzan con fuerza hasta nuestros dias (22) - respecto al establecimiento de una Justicia Constitucional concentrada a partir de la instalación de los Tribunales Constitucionales, en Europa habia predominado la corriente -todavía vigente en Francia con el Conseil d'Etat Français- de confiar la tutela de las disposiciones constitucionales a un órgano político especial, como lo fue en un inicio el Senado Conservador establecido por la Constitución Francesa de 22 de Frimario del Año VIII de-

(20) GARCIA DE ENTERRIA, Eduardo. La Constitución como Norma y el Tribunal Constitucional; Ed. Civitas S.A., Madrid, 1985; pp. 55-56

(21) Op. Cit.

(22) Teoría Pura del Derecho; México, UNAM, 1979. Teoria General del Derecho y del Estado; México, UNAM, 1974. 
bido al Abate SIEYES (23), sobre el que descansaba la idea de una segunda cámara defensora de la Constitución (Sénat Conservateur). y que luego fuera acogido por la Constitución Francesa de 11 de enero de 1852, Art. 29, para luego constituir al Senado en Haute Cour de Justice en las acusaciones contra ministros y otros asuntos de justicia política (24).

Al lado de ello, como antecedente a la obra de KELSEN, el pensamiento europeo también se hallaba inclinado desde tiempo atrás por la existencia de un poder neutro, moderador o armónico, que intervenga con su arbitración a la solución de los conflictos de poder suscitados entre el Parlamento y el Ejecutivo, de acuerdo con los principios divulgados por BENJAMIN CONSTANT en los primeros años del Siglo XIX (25), y que ha sido consagrado en varias Cartas Constitucionales posteriores a 1945, sobre todo tratándose de países preponderantemente parlamentarios.

El Sistema de Control Concentrado de la Constitucionalidad. Sistema de Justicia Constitucional Ad-Hoc o Sistema Europeo, basa su estructura en la existencia de un Organo del Estado, diferente y autónomo de los tradicionales Organos Legislativo, Ejecutivo y, sobre todo, Judicial; que ha de ejercer el control de la Constitucionalidad a partir de la aplicación de una privativa jurisdicción constitucional. Es decir, a esta Corte Constitucional, compuesta por Magistrados ajenos orgánicamente al Poder Judicial, la Constitución le reserva el derecho y el deber excluyente y exclusivo de determinar la inconstitucionalidad de una ley o de un acto de gobierno y, por ende, la facultad de derogar con efectos rescisorios y carácter ERGA OMNES dicha ley o establecer los mecanismos de corrección frente al acto inconstitucional. La actuación de la Corte Constitucional resultará, así, independiente de la de los demás Organos del Estado y operará a impulso de quienes constitucionalmente resulten legitimados para disponer de la acción de inconstitucionalidad de las leyes o de las acciones de garantia constitucio-

(23) FIX-ZAMUdiO, Héctor. Op. Cit. pp. 16-17. Ver también SCHMITT. Carl. Op. Cit. pp. 37-38.

(24) Art. $9^{\circ}$ de la Ley Constitucional de 24 de febrero de 1875.

(25) FIX-ZAMUDIO, Héctor. Op. Cit. p. 17. 
nal, y todas las demás que la Constitución de cada Nación permita por adición, como, por ejemplo, el dirimir los conflictos de competencia entre los diversos estados, naciones, regiones o autonomías.

Es interesante acotar aquí que, como ya se señalara (26) y fuese anotado por FIX-ZAMUDIO, paralelamente al nacimiento de la Justicia Constitucional concentrada a partir del nacimiento de Tribunales Constitucionales especializados, ha surgido también una nueva disciplina científica dentro del Derecho: el Derecho Procesal Constitucional que va a determinar los presupuestos, reglas, principios y lineamientos del procedimiento ante la Corte Constitucional, que se va a diferenciar del Derecho Constitucional Procesal que supone las reglas del proceso ordinario elevadas, por su carácter esencial, a rango constitucional, y que se condensan en la institución del Debido Proceso Legal, Tutela Judicial Efectiva o, como se le conoce en el original Derecho Anglosajón del cual parte con la Bill Of Rigths en Inglaterra y la Enmienda XIV de la Constitución de los Estados Unidos: el DUE PROCESS OF LAW; que no es otra cosa que el conjunto de disposiciones materiales de la aplicación de la justicia integradas en garantías fundamentales, sistematizadas para la adecuada prestación de la justicia que la propia Constitución exige, y que no tienen otra finalidad que permitir el acceso del justiciable a un proceso judicial justo, equitativo, imparcial y definitivo.

Frente a estas dos grandes categorías de Justicia Constitucional, nos encontramos con una tercera que, no siendo mayoritaria, ha inspirado a un importante sector de Constituciones contemporáneas: las inspiradas en el Sistema Soviético y que podríamos denominar el Sistema Socialista. En este sistema de Justicia Constitucional, la tutela de la supremacía constitucional se deposita en el propio Organo Legislativo. En este caso, corresponde al propio Parlamento decidir por sobre las infracciones constitucionales de las leyes por el mismo expedidas, de los actos del Ejecutivo y de

(26) Ver Supra cita No. 13. Ver, además, Héctor FIX-ZAMUDIO, III La Jurisdicción como función esencial del Estado Moderno; en: Función del Poder Judicial en los Sistemas Constitucionales Latinoamericanos; Inst. de Investigaciones Jcas., UNAM, México, 1977, p. 13. 
los particulares, si así fuese establecido por el correspondiente Sistema Juridico (27).

Ahora bien, como es anotado con agudeza por el propio FIXZAMUDIO (28), y es perfectamente constatable en el Derecho Comparado, ninguno de estos tres sistemas se presenta quimicamente puro, en su prístina concepción: sino que se han venido entremezclando, interaccionando $:$, inclusive, combinándose en algunos Ordenamientos Juridicos en aras te un mejor resultado y findlidad, de manera que al tratar de estas tres grandes divisiones estamos haciendo, por sobre todo, un ejercicio académico cuyo objeto es la mejor conceptualización del Sistema Jurídico y su Justicia Constitucional a efectos de nuestro anúlisis.

\section{IMPORTANCIA DE LA JUSTICIA CONSTITUCIONAL}

La importancia de la Justicia Constitucional resulta ahora innegable. El verdadero equilibrio de los poderes o, como modernamente se conoce, el de las funciones competenciales de los diferentes Organos del Estado, hace necesario la existencia de una instancia autónoma que interprete adecuada y definitivamente los postulados constitucionales, determinando también con imparcialidad y autonomía política las violaciones constitucionales cometidas tanto desde el Legislativo a través de leyes y normas inconstitucionales, como del Ejecutivo a través del exceso de poder manifestado en actos inconstitucionales cuya forma puede ser diversa y variable. También el Poder Jurisdiccional puede estar incurso en las violaciones constitucionales a través de actos o normas inconstitucionales, cuanto por la ausencia del respeto a la garantía del Debido Proceso Legal.

Por otro lado, también resulta ahora indiscutible, el que los textos constitucionales no contienen fórmulas estáticas ni valores inmutables, sino que por su propia racionalidad, contienen postulados proyectados siempre hacia el porvenir, de manera históricamente dinámica, precisamente por el contenido axiológico y poli-

(27) FIX-ZAMUDIO, Héctor. Veinticinco años de Evolución de la Justicia Constitucional. Op. Cit. p. 18.

(28) Op. Cit. 
tico (29) de sus postulados. A ello contribuirá, indudablemente, la doctrina constitucional con las modernas corrientes de Interpretación Constitucional y la Mutación Constitucional (30).

$Y$ es que tradicionalmente se ha entendido que siendo la Corstitución la norma jurídica de más alto rango, la hermeneútica que le resulta aplicable es la tradicional para la interpretación de las normas jurídicas ordinarias del sistema jurídico. Sin embargo, las modernas corrientes de interpretación constitucional, a partir precisamente de la aplicación de la Justicia Constitucional, ha cambiado de plano estas tradicionales concepciones que fueron inicialmente formuladas y sistematizadas por VON SAVIGNY, y después profusamente desarrolladas por tratadistas como FRANCESCO MESSINEO (31) y Emilio BETTI (32).

(29) Cuando nos referimos al contenido político de la Constitución, no lo hacemos en el concepto vulgar de politica en tanto componenda y ambición de poder. Nos referimos a los que la Ciencia Política define como política, esto es, la distribución, bajo criterios predeterminados, de los ámbitos competenciales del ejercicio del poder del Estado. Por ello es que, siguiendo a Konrad HESSE, hemos definido a la Constitución norma politica antes que norma juridica. Ver: QUIROGA LEON, Anibal. La Interpretación Constitucional; Op. Cit. p. 324.

(30) Op. Cit. p. 325. Ver alli la cita de Francisco RUBIO LLORENTE en el Prólogo a la obra de Enrique ALONSO GARCIA, La Interpretación de la Constitución, Centro de Estudios Constitucionales, Madrid, 1984; donde concluye: "pues ni la Constitución es una norma, ni es elemento necesario del concepto de norma la generación de obligaciones (...), ni por último, tienen la misma naturaleza o los mismos efectos que las normas contenidas en la Constitución. .." Sobre Mutación Constitucional, ver Konrad HESSE, Escritos de Derecho Constitucional-Selección, Centro de Estudios Constitucionales, Madrid. 1983. Trad. del Prof. Pedro CRUZ VIDALON.

(31) MESSINEO, Francesco. Conocimiento, Interpretación e Integración de las Normas. La Obra del Intérprete: técnica, dogmática y sistemática del Derecho. Aplicación del Derecho; Mimeo, P.A. de Derecho de la PUC del Perú, Lima, 1977.

(32) BETTI, Emilio. Interpretación de la Ley y de los Actos Juridicos; Ed. Revista de Derecho Privado, Ed. Revista de Derecho Financiero, EDERSA; trad. y prólugo de José Luis DE LOS MOZOS, Madrid, 1975. 
En efecto, ya no sólo se considera a la Constitución como el vértice superior del Ordenamiento Jurídico, sino que como norma politica es continente de principios y postulados fundamentales para la organización social, política y económica de la Nación, los que por su propia naturaleza y finalidad han de tener una vigencia históricamente dinámica, cambiante en el tiempo y en el espacio. De allí, pues, que los esquemas de la interpretación jurídica tradicional resulten estrechos y ampliamente superados por una necesidad y requerimiento mucho mayor de aprehender las esencias constitucionales y políticas de las que dependen la estructuración permanente de la Nación.

Es evidente que la Constitución moldea los pilares básicos de un país, en tanto que la realidad de éste condiciona a su vez la propia vigencia constitucional en una constante interacción que es menester descubrir y manejar con acierto. $Y$ también es verdad que la Constitución vincula y obliga a todos, pero la eficacia de la mayoría de sus normas se caracteriza por los Principios Informadores o Inspiradores antes que por mandatos directos (33). Por todo ello es que la hermeneútica tradicional resulta incompleta pues no llega a distinguir aquello, por lo que se ha generado una nueva visión de lo que debe ser la interpretación del texto constitucional, sobre todo a partir de la Justicia Constitucional concentrada en países como Suecia, Italia, Alemania y España en donde este es el sistema de Justicia Constitucional adoptado.

Paralelamente a ello, también la doctrina constitucional moderna -sobre todo a partir del tratadista alemán LASALLE en 1862 con su histórico discurso berlinés Ueber Verfassung Wessen(34) se ha descubierto la Mutación Constitucional como un principio rector que permite la variación histórica del texto constitucional sin necesidad de pasar por el trauma de la reforma total o parcial del propio texto normativo de la Constitución. Por ello, el principio de la Mutación Constitucional es un elemento imprescindible en la moderna hermeneútica constitucional y permite la aplicación de los sistemas axiológicos y políticos que van cambiando

(33) QUiRoga LEON, Anibal. Op. Cit. p. 325.

(34) Citado por GARCIA DE ENTERRIA, Eduardo. Op. Cit. p. 42. 
con la realidad dinámica de una Nación (35). La modernización de la Constitución, su adecuación con la cambiante realidad $\mathbf{y}$, en definitiva, su propia supervivencia fortificada -y no debilitada-por el paso del tiempo, es una consecuencia directa de una adecuada interpretación constitucional de acuerdo a los modernos criterios existentes y al manejo de los criterios adecuados de la Mutación Constitucional.

Por ello podemos concluir, junto con el tratadista italiano Mauro CAPPELLETTI (36), que "El genio del hombre ha descubierto el instrumento más perfeccionado de la relativización de los postulados constitucionales, haciéndolos flexibles a una interpretación autorizada que permita su permanente adecuación al sistema politico y a la realidad histórica a través de la justicia constitucional. Por medio de esta institución se confía a jueces imparciales la humanización de lo absurdo, la concreción de los abstracto, la correcta aplicación y realidad históricamente actual de los valores supremos, que serian fria y estáticamente irrealizables si se consideraran encerrados y cristalizados en las fórmulas normativas de la Constitución". Por ello, concluye CAPPELLETTI, "el sentido de

(35) Ferdinand LASALLE sostenía ya en 1862 que la Constitución escrita sería una mera hoja de papel, ya que lo que cuenta es la Constitución real y efectiva 〈(wirklichen Verfassung》), expresión de las relaciones fácticas de poder, normalmente silenciadas (...) en el texto legal. Op. Cit. Sobre el tema también se ha afirmado, citando a LASALLE, que 《la constitución no es aquel papel escrito al que todos recurren cual oráculo, sino las relaciones de poder que se hallan en constante movimiento y mutación en un país, lo que -aunque resulte paradógico-es la base de la sólida estructura, organización y unidad del Estado. El reconocimiento del Estado y del Derecho no debe olvidar que sólo cabe hablar de Constitución si se la afirma, dentro del dinamismo político, económico y social, con ese esencial carácter relativamente estático. Por eso la Constitución no es proceso sino producto, no actividad sino forma de la actividad. forma abierta a través de la cual pasa la vida, vida en forma y forma nacida a la vida"; en: Las Vueltas de la Constitución, artículo de Opinión escrito desde Madrid por Jorge MELO-VEGA CASTRO y Aníbal QUIROGA LEON para el Diario "La República" en su edición del 6 de junio de 1985 , p. 13.

(36) CAPPELLETTI, Mauro. Op. Cit. pp. 74-75; cit. por Héctor FIX-ZAMUDIO; op. cit. p. 163. 
la Justicia Constitucional es la vida, la realidad y el porvenir de las Cartas Constitucionales de muestra época" (37).

\section{EVOLUCION DE LA JUSTICIA CONSTITUCIONAL EN AMERICA}

Es muy difícil seguir una trayectoria lineal en el desarrollo de la defensa constitucional en América, puesto que mientras en los Estados Unidos y el Canadá - bajo el sistema anglosajón de la Judicial Review - ha sido paulatino y continuado, en los ordenamientos jurídicos latinoamericanos se advierte una gran variabilidad dentro de una trayectoria que FIX-ZAMUDIO califica de ascendente (38).

Por ello, del análisis somero que se ha realizado de los tres grandes sistemas de Justicia Constitucional imperantes en la actualidad, se concluye que desde 1940 en adelante el control de la constitucionalidad de los actos de la autoridad ha sufrido un desarrollo que la doctrina constitucional no duda en calificar de sorprendente (39). Si bien es cierto que la Justicia Constitucional no es una institución del presente Siglo sino que hunde sus raíces en el nacimiento y evolución del Estado moderno y aflora después de un proceso calificado de lento y atormentado ya de una manera definida después de las dos grandes luchas libertarias de las postrimerías del Siglo XVIII, el proceso a partir de entonces ha sido también el de una paulatina consolidación con el convencimiento de que ya no era suficiente el consagrar los valores supremos de la organización social y política en un documento escrito denominado Constitución Politica, sino que debian además de establecerse

(37) Sobre la capital importancia de la Justicia Constitucional ejercida a través de Tribunales Constitucionales, el propio G ARCIA DE ENTERRIA señala: ( $E l$ tema del Tribunal Constitucional es posiblemente el tema central de nuestra Constitución (española); me atrevo a decir (...) que es aquel en que esta Constitución se juega sus posibilidades y su futuroly; en: La Posibilidad Jurídica del Tribunal Constitucional; Revista Española de Derecho Constitucional, Centro de Estudios Constitucionales, Madrid, Vol. 1, Núm. 1, 1981, pp. 35 y ss. Cit. por Aníbal QUIROGA LEON, El Tribunal de Garantiás Constitucionales ante el dilema de Ser o no Ser; en: THEMIS No. 4, Segunda Epoca, Facultad de Derecho de la PUC del Perú, Lima, 1986; pp. 40 y ss.

FIX-ZAMUDIO, Héctor. Op. Cit. p. 19. 
alli los mecanismos necesarios para la garantía consecuente de esos valores supremos, los que cada día deben de lograr su mayor efectividad. Sin embargo, tampoco puede afirmarse que a la fecha exista un mecanismo de control constitucional que tenga un mayoritario consenso, como el método más adecuado para lograr la efectividad de los principios establecidos en las normas constitucionales, previniendo su violación y restaurando y reparando el orden fundamental cuando se hubiese infringido (40).

Pero al lado de esta constatación. FIX-ZAMUDIO (41) apunta otra: en nuestra época, cualquiera sea la orientacion politica de los Ordenamicntos Politicos de nuestros Estados -.particularmente en nuestra sismica rcalidad al decir de BASADRE- ya no es posible prescindir de uno o varios Sistemas de Justicia Constitucional. que se van perfeccionando paulatinamente orientados todos ellos a la (máxima) aspiración mencionado por JELLINECK como una esperanza todavia lejana en los albores de muestro Siblo que la se esperanza todavia lejana en los albores de muestro Siglo que ia se acaba: "UN ORDEN JURIDICO CONSTITUCIO V.4L" (42).

\section{LA JUSTICIA CONSTITUCIONAL EN EL SISTEMA PERUANO}

\subsection{Antecedentes}

Señalaba el jurista peruano ZARATE POLO (43) en 1957 que las leyes deben reflejar la voluntad popular y, además, obedecer a una necesidad social impostergable. Tales requisitos extrínsecos de la ley reunidos significan un gran esfuerzo para plasmar la sentida necesidad de alcanzar, mediante un procedimiento breve y eficaz. la defensa de los derechos garantizados por la Constitución.

(40) Op. Cit. p. 149

(41) Op. Cit. p. 150

(42) Op. Cit.

(43) ZARATE POLO, Marco Antonio. La Protección Judicial de la Constitucionalidad; en: Revista de Jurisprudencia Peruana, Nos. 159, 160 y 161 , abril-junio, Lima, 1957; p. 383. 
Por ello, cuando se estudia el constitucionalismo peruano, en la medida en que en ningún momento ha variado la sustentación republicana representativa y democrática de nuestra organización política, las anteriores Constituciones sirven necesariamente de fuente supletoria de interpretación vigente, sobre todo cuando de su espíritu se advierte un proceso histórico de consolidación de las garantias fundamentales.

En primer término, hay que advertir que hasta la vigencia de la Constitución de 1979, mientras la evolución ha sido notablemente progresiva en cuanto a la simple declaración de derechos y al establecimiento de garantias, los medios de control se fueron debilitando cada vez más, sobre todo en cuanto concierne al control del órgano político, para llegar a la preeminencia del control jurisdiccional en la Constitución de 1933 que, sin embargo, no llegó a ser eficiente debido a la ausencia de una adecuada interpretación judicial y al vacio legislativo en cuanto al desarrollo reglamentario de la Justicia Constitucional en el Perú, a lo que sin duda ayudó la ausencia de una perspectiva histórico-jurídica que visualizara esto y le dotara de fundamento. No obstante, SOUSA y DANOS (44), sostienen que en mayor o menor grado no ha estado exenta de nuestra historia constitucional positiva una cierta preocupación por el control de la constitucionalidad de las normas, apareciendo en casi todos, según citan a ZARATE POLO (45), el establecimiento de diversos mecanismos de Defensa Constitucional de carácter Político, siempre atribuidos al Legislativo, que si bien nunca configuraron un sistema de Justicia Constitucional en los términos definidos, cuando menos evidenciaban la inten ción del establecimiento de alguna forma de control.

Si tuviéramos que hacer un somero repaso de las Constituciones nacionales y la formulación de sus garantías, tendríamos que precisar lo siguiente:

(44) SOUSA CALLE, Martha y DANOS ORDOÑEZ, Jorge. Op. Cit. p. 287 Citan a Marco Antonio ZARATE POLO, op. cit. p. 396.

(45) 〈(En todas las Constituciones, sin excepción, se han considerado normas que atribuyen al Poder Legislativo la vigilancia del cumplimiento de sus normas, configurándose varios sistemas de diferente eficacia $e$ intensidad $\rangle$ Op. Cit. y cita No. 3 
CONSTITUCION DE 1823. - Ya distinguía entre los derechos sociales e individuales: sin embargo estos no fueron separados sistemáticamente en Capitulos diferentes. Los derechos sociales se entienden incorporados en el texto de la integridad de la Constitución, como lo señalaba su Art. $193^{\circ}$.

CONSTITUCION DE 1826.-. Se dedica también en un sólo Capítulo -De las Garantias-- al examen de estas, pero a diferencia de la anterior, trata de explicar el ejercicio del derecho protegido.

CONSTITUCION DE 1828.-- Se dedica también en un sólo Título a las Garantías Individuales y Sociales; pero es digno de resaltar que por primera vez se incorpora como derecho garantizado el Principio de Legalidad y el de la Irreatroactividad de la Le'. Incorpora también de modo explícito la garantía de la independencia del Poder Judicial.

- CONSTITUCION DE 1834.-- Es la primera que separa las Garantías Individuales de las demás en Capítulos diferentes, bajo los epígrafes Garantias Constitucionales y Disposiciones Generales. Como importante contribución, aparece garantizado por primera vez el principio del Debido Proceso Legal contenido, más de cien años después, en la Declaración Universal de Derechos del Hombre de las Naciones Unidas en 1948. Además, por primera vez se configura la garantía de la Libertad Individual.

CONSTITUCION DE 1839. - Al igual que su precedente, separa también sistemáticamente las Garantías Individuales de las otras a las que denomina Garantias Nacionales. Se advierte una marcada tendencia conservadora.

- CONSTITUCION DE 1856. - Conserva la distinción entre las Garantias Individuales y las denominadas Nacionales, estableciendo el Principio de Legalidad para la determinación de las Contribuciones, introduciendo como novedad la Libertad de Asociación. Lo que sí resulta novedoso, y pionero además, es que el embrión de un esbozo de Justicia Constitucional puede ser hallado en esta importante -pero de breve vigencia- Constitución, pues en su Art. $10^{\circ}$ establecía: "Es nula y' sin efecto cualquier ley' en cuanto se 
cononga a la Constitución", siendo - como se ha anotado- el primero, y a la postre el único, dispositivo constitucional que de manera expresa consagraba el principio de la invalidez y nulidad de todo acto legislativo dictado en contravención a la Constitución $140)$.

CONSTTLC CON DE 1860 . - Mantenía la división de las (iarantías, y el establecimiento del Principio de Legalidad en materia tributaria, al que le adiciona una nueva idea: la proporcionalidad a la facultad de los contribuyentes o criterio de la capacidad contributiva.

CONSTITUCION DE 1920.-. En el rubro de las denominadas Garantias Nacionales repite la prohibición de los fueros personales y los privilegios, el Principio de Legalidad en materia impositiva: introduciendo por primera vez frente al Derecho individual de la Libertad Personal, el Recurso de Habeas Corpus (Art. 24), como medio de defensa y garantía frente a la prisión indebida (47).

CONSTITUCION DE 1933. - Introduce el concepto de las Garantias Nacionales y Sociales frente a las Garantias Individuales. Se advierte un enorme crecimiento de las primeras con relación a los textos constitucionales precedentes. No se habla aún de Amparo. pero se mantiene la Acción de llabeas Corpus en su Art. 69, que luego va a dar lugar al denominado Habeas Corpus Civil de que trata el decreto Ley 17083 del 24 de octubre de 1968, en tanto que el original y verdadero Habeas Corpus se cautela en el Código de Procedimientos Penales de 1940 (48).

(46) Op. Cit. y p. 288

(47) GARCIA BELAUNDE, Domingo. El Habeas Corpus Interpretado; Instituto de Investigaciones Jurídicas, PUC del Perú, Lima, 1971, pp. 11-12

(48) En 1931, durante los debates respecto a la reforma del Código Civil de 1852 iniciados en 1923, se hace de conocimiento el Anteproyecto Constitucional de la Comisión Villarán que, concebido con buen criterio técnico e independiente, al decir de BASADRE, fue en varios aspectos superior a la Carta de 1933. Allí se facultaba a los jueces a desaplicar las normas ordinarias contrarias a la Constitución, con cargo a una revisión ex-officio y en última instancia de la Corte Suprema de Justicia de la 


\subsection{Situación actual}

Resulta así evidente que el sistema actual que rige nuestra Justicia Constitucional nacional no surge plena y únicamente de la Constitución de 1979, vigente desde el 28 de julio de 1980, como muchos creen, sino que nace históricamente desde tiempo atrás, casi como un resultado natural sin que se le hubiere perfilado así por la intención del constituyente o legislador, como ya se ha visto de los antecedentes reseñados. Al margen de la breve -por su vigencia efectiva-Constitución de 1856 a la que ya nos hemos referido (49), los orígenes prácticos reales se pueden hallar con la Constitución de 1920 y la doctrina sentada en aquel año por la Corte Suprema de Justicia de la República al establecer la primacía del texto constitucional por sobre la normatividad ordinaria, cuando sentenciaba: "A la ley Fundamental se encuentran fatalmente subordinadas todas las demás, siempre secundarias (...) |.1. en la Administración de Justicia. carecen de aplicación las leves inconstitucionales. . ."(50).

Como también se ha anotado ya, recién con los Debates de la Comisión Reformadora del Código Civil en 1923 (51) es que se examina la posibilidad de positivizar alguna forma de revisión judicial de las leyes, según la inspiración que confería el Sistema Americano de la Judicial Review en donde tal potestad se reservaba para los Jueces ordinarios. Luego de numerosas discusiones, en que inclusive se debatió la constitucionalidad de una medida como esta (52), así como su amplitud y su margen de competencia, se con-

República. SOUSA CALLE, Martha y DANOS ORDOÑEZ, Jorge. Op. Cit. p. 289. Ver asimismo el excelente trabajo de Domingo GARCI $A$ BELAUNDE, Legislación Peruana sobre el Habeas Corpus (1897-1968): en: Rev. de Der. y C. Políticas, Vol. 39, Nos. 1, 2 y 3; ene-dic., 1975, Lima, pp. 27 y ss.

(49) Ver Supra 6-1 Constitución de 1856.

(50) Acción de Habeas Corpus interpuesta por doña Cecilia Althaus de Pardo; cit. por BUSTAMANTE Y CISNEROS, considerado como un leading case peruano, comparable al de Marbury urs. Madison (ver cita No. 15 Supra); cit. por SOUSA CALLE, Martha y DANOS ORDOÑEZ, Jorge; op. cit. pp. 288-289.

(51) Ver cita No. 48 Supra.

(52) Actas de la Comisión Reformadora, p. 52; op. cit. 
vino en claborar una fórmula que facultara a todos los jueces a desaplicar las normas inconstitucionales, la que no vería la sanción legislativa hasta la promulgación del Código Civil de 1936.

En efecto, el Art. 236 de la Constitución Política del Estado de 1979, vigente en la actualidad, señala textualmente:
"Art. 236.- En caso de incompatibilidad entre una norma constitucional y una legal ordinaria, el juez prefiere la primera. Igualmente, prefiere la norma legal sobre toda norma subalterna".

Esta es una norma Constitucional que establece uno de los mecanismos de Justicia Constitucional vigente en el Perú de hoy, y es una norma de garantia de la constitucionalidad de la ley -tanto formal como material - por que pretende cautelar la jerarquía normativa de nuestro ordenamiento jurídico expresamente consagrada en el Art. $87^{\circ}$ de la propia Carta Constitucional que establece la pirámide kelseniana de estructuración del orden jurídico interno (53).

Como se puede apreciar, el antecedente normativo inmediato de esta disposición es, sin duda alguna, el Art. XXII del Título Preliminar del Código Civil de 1936 -ahora derogado (54)-que textualmente señalaba:

\section{“Art. XXII. - Cuando hay incompatibilidad entre una norma constitucional y una legal se prefiere la prime- ra".}

Al margen de la mayor bondad de técnica legislativa de uno y otro texto normativo - particularmente preferimos la formulación

(53) "Art. 87. La Constitución prevalece sobre toda otra norma legal. La ley. sobre toda otra norma de inferior categoría, y asi sucesivamente de acuerdo a su jerarquía jurídica. $(\ldots)^{\prime \prime}$

(54) El Código Civil de 1984 no ha repetido esta disposición debido, precisamente, a la pre-existencia -para el-del Art. $236^{\circ}$ de la Constitución Política del Estado. Ver: QUIROGA LEON, Anibal, Los Derechos Humanos, el Debido Proceso y las Garantías Constitucionales de la Administración de Justicia, op. cit. pp. 161-163. 
original del Código Civil de 1936-, se debe tener en cuenta que, sin duda alguna, para el legislador de 1936 era ya eviderte la necesidad y realidad de un Sistema de Justicia Constitucional: el Sistema Americano o difuso o, también denominado, de la Judicial Review de control de la constitucionalidad, con la importante variante que la inconstitucionalidad determinada y judicialmente declarada sólo afectaba al caso concreto (Inter Alios Iuditio), y no con los efectos derogatorios o rescisorios ERGA OMNES del original Sistema Americano (55).

Posteriormente, en 1963 la Ley Orgánica del Poder Judicial - actualmente en vigencia - reitera esta situación, determinando inclusive el trámite a seguir por el juez que proceda a aplicar esta disposición de inconstitucionalidad de una norma legal. En efecto, el Art. $8^{\circ}$ de esta norma legal señala textualmente lo siguiente:

"Art. $8^{\circ}$ - Cuando los jueces y Tribunales, al conocer cualquiera clase de juicios, encuentren que hay incompatibilidad entre una disposición constitucional y: una legal, preferirán la primera.

Si no fueran apeladas las sentencias de primera instancia en que se aplique este precepto, se elevarán en consulta a la Primera Sala de la Corte Suprema.

La sentencia de segunda instancia se elevarán en contsulta a la Primera Sala de la Corte Suprema, si no se interpusiese el recurso de mulidad.

Los jueces y Tribunales no aplicarán decretos y reglamentos del Poder Ejecutivo o cualquier otra autoridad contrarios a la Constitución y las leyes".

Como ya se ha anotado, esta potestad jurisdiccional de determinar libérrimamente la constitucionalidad de la leyes y demás normas legales, se inscribe dentro del sistema difuso o de Judicial Review de control de la constitucionalidad. Vale decir, la posibilidad de que sea el propio Poder Judicial -en ejercicio del control inter-órganos de que habla LOEWENSTEIN (56) - proceda a apli-

(55) Ver Supra 3. Categorías Fundamentales.

(56) LOEWENSTEIN, Karl. Teoría de la Constitución; Eds. Ariel, Barcelona, 1964. 
car la Justicia Constitucional desaplicando leyes y normas de inferior jerarquia por inconstitucionalidad en los conflictos intersubjetivos sometidos a su conocimiento y competencia.

También hemos señalado que el control de la constitucionalidad tiene tres grandes sistemas (57). Entre ellos: el europeo o de Justicia Constitucional concentrada o Ad-Hoc. generalizado a partir de la Constitución austríaca de 1920 y de la obra de HANS KELSEN: en el cual un órgano autónomo especializado y constitucionalmente designado para ello, tiene la potestad de revisar la constitucionalidad de las normas legales y los actos de poder, estableciendo al respecto declaraciones generales $E R G A$ OMNES de plenos efectos derogatorios o rescisorios. El Sistema 1mericano o de Control Difuso (también denominado de la Judicial Review). permite - como ya se ha dicho-que sea el aparato judicial ordinario el que desarrolle la función del control de la constitucionalidad, sea con efectos derogatorios o rescisorios $E R G .4$ OMNES o con efectos particulares limitados al caso concreto materia del litigio donde sea determinada la norma inconstitucional.

Nuestro Ordenamiento Jurídico Nacional contiene, hoy por hoy, estos dos grandes sistemas (58), en lo que podríamos válidamente considerar un Sistema Mix to de Justicia Constitucional: por un lado la Constitución de 1979 , en sus Arts. $296^{\circ}$ y siguientes, ha creado un órgano $A d-H o c$ de control de la Constitucionalidad de las normas y actos de poder en el Perú, diferente y diferenciado del Poder Judicial, y que recibe la denominación de Tribunal de Garantias Constitucionales, cuyas decisiones en materia de inconstitucionalidad de leyes y normas tienen efectos derogatorios $E R$ GA OMNES (59); en tanto que, por otro lado, se mantiene la facultad de los Jueces y Tribunales ordinarios, en cualesquiera de sus

(57) Ver Supra

3. Categorias Fundamentales.

(58) QUIROGA LEON, Anibal. Op. Cit. y p. 164.

(59) "Art. $296^{\circ}$. El Tribunal de Garantías Constitucionales es el órgano de control de la Constitución (...)"

"Art. $301^{\circ}$. No tiene efecto retroactivo la sentencia del Tribunal que declara inconstitucional una norma en todo o en parte".

“Art. $302^{\circ}$. El Tribunal comunica, al Presidente del Congreso la sen- 
instancias, grados y jerarquías (inclusive lat Justicia de Paz) le calificar la constitucionalidad de una noma clue debe ser materia de aplicación en una causa de su conocimiento y competencia.

En este último caso, a diferencia del Sistema 1 moricano puro, el efecto inconstitucional sólo afecta a la causa concreta en donde esta determinación se presenta alcanzando sólo a las partes en litigio (Inter Alios huditio). manteniendo por el contrario, la norma en cuestión, su plena vigencia dentro del Ordenamiento Jurídico Nacional. Ls Principio General del Derecho. también consagrado en norma positiva tanto en la Constitución (Art. 233 ${ }^{\circ}$. inc. 6to.), como en la Ley Orgánica del Poder Judicial de 1963 (Art. $23^{\circ}$, inc. a), como en el Código Civil en vigencia (Art. VIII de su Titulo Preliminar), y su antecedente en el Art. XXIII del Titulo Preliminar del Código Civil de 1936, la sujeción del juez peruano al texto expreso de la ley positiva, única fuente vinculante en nuestro derecho, de manera que jamás pueda incurrir en actos omisorios de Administración de Justicia amparado en defecto, deficiencia, oscuridad o vacio normativo. Sin eṇbargo, en mérito de lo anterior, sin dejar jamás de Administrar Justicia --pues incurriría en Dolito de Prevaricato además de la sanción administrativa correspondientepuede apartarse del texto expreso de una ley, o de una norma general de inferior jerarquia, cuando determine, libérrimamente por sí y ante si, cx-officio, la inconstitucionalidad de la misma (60).

Y nuestro Sistema Concentrado de Justicia Constitucional establecido en la Constitución de 1979 con el establecimiento del Tribunal de Garantias Constitucionales supone también la posibilidad de determinar, ahora sí con efectos derogatorios o rescisorios

tencia de inconstitucionalidad de normas emanadas del Poder Legislativo. El Congreso en mérito del fallo aprueba una ley que deroga la norma inconstitucional.

Transcurridos cuarenticinco días naturales sin que se haya promulgado la derogatoria. se entiende derogada la norma inconstitucional. El Tribunal ordena publicar la sentencia en el Diario Oficial".

(60) La inconstitucionalidad determinada judicialmente es una facultad o atribución libre del Juez o Tribunal y no un derecho de la parte litigante. Esta puede proponer tal situación, pero en ello el juzgador mantiene el más absoluto poder discresional. 
ERGA OMNES, la inconstitucionalidad de una ley o norma legal de inferior jerarquía (61).

Pero también puede el Tribunal de Garantias Constitucionales, en lo que FIX-ZAMUDIO (62) denomina Jurisdicción Constitucional de la Libertad, conocer en casación las sentencias reca idas en las acciones de Garantías de Amparo y Habeas Corpus, luego de haber terminado su tramitación previa ante el Poder Judicial ordinario (lo que también le otorga a este en tales acciones control de la constitucionalidad, reafirmando la mixtura de los sistemas (63) - siempre y cuando el lesionado y demandante hubiese visto denegada su pretensión, ya que cuando tales acciones de Garantía Constitucional son amparadas finalmente por el Poder Judicial ordinario, no hay lugar al recurso de casación en cuestión (64).

Es por esta situación, señala CHIRINOS SOTO (65), que se explica la composición por tercios de los miembros del Tribunal

(61) Decretos Legislativos, Normas Regionales de carácter general y Ordenanzas Municipales.

(62) FIX-ZAMUDIO, Héctor. La Protección Procesal de los Derechos Huma. nos ante las Jurisdicciones Nacionales; Ed. Civitas S.A. -UNAM, Inst. de Investigaciones Jcas., Serie B. Estudios Comparativos, No. 21; Madrid, 1982 .

(63) Ver Supra y cita No. 58

(64) "Art. $298^{\circ}$. El Tribunal de Garantías Constitucionales (...) es compe. tente para:

$(\ldots)$

2. - Conocer en casación las resoluciones denegatorias de la acción de habeas corpus y la acción de amparo, agotada la via judicial". Inclusive, agotada la via interna, dentro de la misma tónica, y siempre que la posición final sea contraria a la pretensión del accionante lesionado, puede ocurrir a la jurisdicción internacional en esta materia según los tratados signados por el Perú (Art. $305^{\circ}$ de la Constitución Política del Estado). En este caso, básicamente a la Comisión Interamericana de Derechos Humanos que puede permitir el acceso a la Corte Interamericana de Derechos Humanos de conformidad con lo dispuesto en el Pacto de San José de 1969 o Convención A mericana sobre Derechos Humanos.

(65) CHIRINOS SOTO, Enrique. La Nueva Constitución al alcance de todos; Ed. Andina, Lima, 1979. 
de Garantias Constitucionales en los tres Organos del Estado, en proporción equivalente (66).

7. CONCLUSION

Finalmente, a modo de conclusión podremos afirmar que el sistema mixto de Justicia Constitucional que nuestro Ordenamiento Jurídico ha terminado diseñando como producto histórico y que se contiene en la Constitución de 1979 es uno de los más perfecto posibles, pues combina extraordinariamente bien dos de los más importantes sistemas de Justicia Constitucional del mundo contemporáneo: el concentrado o europeo, y el difuso o americano. En puridad, la constitucionalidad de las normas en el Perú está firmemente garantizada en el texto constitucional, como lo están las acciones de garantía en la preservación de los Derechos Fundamentales. Sin embargo, no somos ciegos a la realidad que nos circunda $-y$ oprime-, por lo que entonces cabe la obvia interrogante: ¿Por qué el desface entre la norma y la realidad? La respuesta podría ser fácil acusando alguna insuficiencia normativa, exigiendo más claridad legislativa o la necesidad de un mayor reglamentarismo al que estamos tan habiatuados. Sin embargo, intentando una respuesta un tanto más compleja podríamos afirmar que el problema en modo alguno está en las normas, por lo que no debemos perder esfuerzos buscando entre ellas, pues tenemos ante nosotros un sistema mixto casi idílico. El problema hunde sus raíces -con lamentable profundidad - fundamentalmente en el clcmento subjetivo que acciona al interior del Sistema Juridico. No olvidemos

(66) Es importante destacar que ni la Constitución de 1979, ni la Ley Orgánica del Tribunal de Garantías Constitucionales, señalan expresamente que a dicho Organo le compete de manera definitiva la interpretación constitucional. El Art. $186^{\circ}$, Inc. 1ero. de la propia Constitución conplica aún más el panorama pues expresamente señala que "son atribuciones del Congreso (...) interpretar las (leyes) existentes". Aquí se presenta una diferencia sustantiva con las normatividades de otros sistemas concentrados de Justicia Constitucional, como el caso de la Ley Fundamental de Bonn y la Constitución Española, donde expresamente se señala que "El Tribunal Constitucional es el intérprete Supremo de la Constitución". Es obvio que tanto el Juez ordinario que aplica la Justicia Constitucional difusa como el Tribunal de Garantías Constitucionales en uso de sus privativas atribuciones, terminan interpretando la Constitución de manera válida y definitiva. Ver sobre el tema Anibal QUIROGA LEON, La Interpretación Constitucional, op. cit. 
que las normas escritas son nada si de por medio no hay un hombre que las interprete y haga realidad, sea este ciudadano, autoridad, legislador o magistrado.

¿Por que hasta la fecha el Tribunal de Garantias Constitucionales ha tenido una actuación marcadamente deficitaria, hasta el punto de lograr que algunos -.con evidente irresponsabilidad y ausencia de perfección histórica-. plantean su desaparición? No obviamente porque el sistema sea negativo o esté mal estructurado, sino porque evidentemente los personajes llamados históricamente a darle vida no han estado. ni mucho menos, a la altura de la responsabilidad histórica que la Nación les encomendara (67).

Del mismo modo, por qué el sistema judicial ordinario en el Perú no ha cjercido debida y adecuadamente la facultad del control de la constitucionalidad, tanto en la facultad difusa como en las acciones de garantia constitucionales vigentes, de una u otra manera, desde inicios del presente Siglo (68). No es tampoco por defecto de la norma legal positiva o constitucional, que como hemos visto es por demás clara y completa. Tampoco lo es por ausencia de real independencia frente al poder. Lo es, en mucho, por una evidente falta de percepción histórica del rol del Juez en el Perú, por un claro defecto de consciencia del papel controlador de la constitucionalidad $-y$ del poder político, por ende-, y per una notoria ausencia de bondad juridica en sus agentes que sólo la capacitación y la mejor selección pueden subsanar.

La timidez frente al poder, la ausencia de una definición clara $y$ valiente de su propio rol y la inexistencia de una verdadera pre-

(67) Ver sobre el particular QU1ROGA LEON, Anıbal, El Tribunal de Garantias Constitucionales ante el dilema de Ser o no Ser, Op. Cit.

Problemas internos de corte minúsculo han comprometido su funcionamiento y ello es de público conocimiento, sin que efectivamente haya cubierto la expectativa que fundadamente se puso en su funcionamiento. Se nos ha dicho que el artículo aqui citado, que critica una postura anormal del Tribunal de Garantias Constitucionales ha de ser respondido en esa misma tribuna en el número 7 en prensa, escrito por un Magistrado que no acepta en modo alguno lo que alli se plantea con honestidad y claridad.

(68) GARCIA BELAUNDE, Domingo. Op, cit. 
paración y capacitación judicial han contribuido, en mucho, para esta situación que es de lamentar muy de veras.

Por ello, sólo potenciando el papel del Tribunal de Garantias Constitucionales y revalorando la necesaria actuación de nuestro Poder Judicial en el imprescindible control del Poder Politico, y acusando el máximo respecto a la Justicia de la Libertad aplicando los valores supremos consagrados con tanto esfuerzo en la Cunstitución Politica del Estado, avanzaremos con paso firme y seguro, no sólo a la consolidación de nuestro Sistema Jurídico Nacional, sino además, al afianzamiento del Sistema Democrático como sistema político de organización social y económica, y a un evidente mayor respecto por los derechos y valores fundamentales en los que se sustenta la vigencia de los Derechos Humanos en el Perú (69).

Arequipa, 24 de abril de 1987

(69) Al referirse a la Constitución española de 1978 y su relación con el Tribunal Constitucional. el Prof. Eduardo GARCIA DE ENTERRIA (La Constitución como Norma y el Tribunal Constitucional, op. cit.) sostiene algo que, siendo vigente para la España democrática de hoy luego de una larguísima dictadura sin Constitución $\mathbf{n}$

Constitución como Norma y el Tribunal Constitucional, op. cit.) sostiene algo que. siendo vigente para la España democratica de hoy luego de una larguisima dictadura sin Constitución ni control del poder politico, creo que puede tener validez entre nosotros: 《En la Constitución de 1978 tiene el vivir de los españoles una firme esperanza. A todos nos corresponde aportar lo que podamos para que esa esperanza no se frustre -frustración que nos arrastraria de nuevo a la tragedia y a la mutilación -$\rangle ;$; p. 34. 